Research Paper

\title{
Cancer Stem Cells of Diffuse Large B Cell Lymphoma Are Not Enriched in the CD45 ${ }^{+} \mathrm{CD} 19^{-}$cells but in the ALDH ${ }^{\text {high }}$ Cells
}

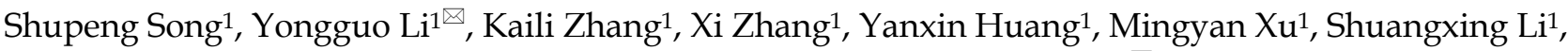 \\ Xue Guan², Tao Yang 3 , Zhiyu Liu ${ }^{4}$, Jie Jiang5, Yunping Luo ${ }^{6}$, Yinghua Lan ${ }^{1}$ \\ 1. Department of Infectious Disease, The First Affiliated Hospital of Harbin Medical University, Harbin, 150000, Hei Longjiang, China. \\ 2. Animal experimental center, The Second Affiliated Hospital of Harbin Medical University, Harbin, 150000, Hei Longjiang, China. \\ 3. Instrument Center, Harbin Veterinary Research Institute, Chinese Academy of Agricultural Sciences, Harbin, 150000, Hei Longjiang, China. \\ 4. Central Laboratory, The First Affiliated Hospital of Harbin Medical University, Harbin, 150000, Hei Longjiang, China. \\ 5. Department of Pathology, The First Affiliated Hospital of Harbin Medical University, Harbin, 150000, Hei Longjiang, China. \\ 6. Department of Immunology, Institute of Basic Medical Science, Chinese Academy of Medical Science and Peking Union Medical College, Beijing,10005, \\ China.
}

$\triangle$ Corresponding authors: Department of Infectious Disease, The First Affiliated Hospital of Harbin Medical University, 23 Postal Street, Nangang District, Harbin, 150000, Hei Longjiang, China. Phone: +86. 0451. 85555197. E-mail: liyongguo@hrbmu.edu.cn (Yongguo Li), lan_yinghua@163.com (Yinghua Lan).

(c) The author(s). This is an open access article distributed under the terms of the Creative Commons Attribution License (https://creativecommons.org/licenses/by/4.0/). See http://ivyspring.com/terms for full terms and conditions.

Received: 2019.03.18; Accepted: 2019.09.12; Published: 2020.01.01

\begin{abstract}
Although the existence of cancer stem cells (CSCs) has been suggested in diffuse large B cell lymphoma (DLBCL), there is still no definitive marker. $C D 45^{+} C D 19^{-}$has been regarded as a potential marker of CSCs in mantle cell lymphoma (MCL). So, we explored the role of CD45 ${ }^{+} \mathrm{CD} 19^{-}$ in DLBCL. However, both CD45 ${ }^{+} \mathrm{CD} 19^{-}$cells and $\mathrm{CD} 45^{+} \mathrm{CD} 19^{+}$cells did not generate tumors until more than 100,000 cells were inoculated in NOD/SCID mice, even CD45 ${ }^{+} \mathrm{CD} 19^{+}$cells generated more and larger tumors, as well as the soft agar colony formation in vitro; The aldehyde dehydrogenase (ALDH) activity was also identified in this study. Only 1,500 ALDH ${ }^{\text {high }}$ cells were enough to generate tumors in mice while the same number of $A L D H^{-}$cells were not. Moreover, both groups formed tumors when more cells were inoculated, but $\mathrm{ALDH}^{\text {high }}$ cells formed more and larger tumors. The similar result was obtained in vitro clonogenicity experiments. OCT4, SOX2, Nanog, and ABCG2 genes did not show any difference in $C D 45^{+} \mathrm{CD} 19^{+}, \mathrm{CD} 45^{+} \mathrm{CD} 19$, $\mathrm{ALDH}^{\text {high }}$ and $\mathrm{ALDH}^{-}$cells. Taken together, CSCs are not enriched in the $\mathrm{CD} 45^{+} \mathrm{CD} 19^{-}$cells but in the $\mathrm{ALDH}^{\text {high }}$ cells in DLBCL cell lines.
\end{abstract}

Key words: $\mathrm{CD} 45^{+} \mathrm{CD} 19-$ - ALDH activity, CSCs markers, diffuse large B cell lymphoma

\section{Introduction}

DLBCL is the most common lymphoid neoplasms worldwide, accounting for about $40 \%$ of non-Hodgkin's lymphoma (NHL) cases in different geographic regions [1]. Roughly $10 \%$ of patients with DLBCL are Epstein-Barr virus (EBV) positive, a higher proportion in the elderly and immunocompromised patients [2]. Resting B cells can be transformed into lymphoblastoid cell line (LCL) by EBV in vitro. LCL-like cells are observed in vivo and typical in EBV-associated lymphoma patients with immunodeficiency [3]. Therefore, LCL provides an important lymphoma model in vitro [4]. However, the pathogenesis of DLBCL is still obscure at present. In addition, there is a risk of relapse or refractory up to $40 \%$ with chemotherapy [5].

An increasing number of evidences show that CSCs exist in many cancers [6-11]. CSCs hypothesis indicates that the reason for tumorigenesis, metastasis and recurrence is related to CSCs in tumors. Recently, a report showed that the existence of "side population" (SP) cells suggested the possibility of CSCs in DLBCL [12] although there were no distinct markers 
for DLBCL CSCs. CD45+CD19- has been identified as a potential marker of CSCs in MCL [13-15]. CD45 CD19- cells isolated from MCL primary patient cells generated tumors in all mice. On the contrary, mice inoculated with $\mathrm{CD} 45^{+} \mathrm{CD} 19^{+}$cells did not generate any tumors [13]. In addition, $\mathrm{CD} 45^{+} \mathrm{CD} 19$ - cells were associated with the chemotherapy resistance and clinical outcomes of patients with MCL [14, 15]. According to the previous study in MCL, we explored to identify whether $\mathrm{CD} 45^{+} \mathrm{CD} 19-$ can be a marker of CSCs in DLBCL.

Cellular activities, such as the ALDH enzymatic activity and the above-mentioned SP cells have been used to identify CSCs populations as well. ALDH is an enzyme in the cytoplasm that facilitates the oxidation of intracellular aldehydes into acids. It is expressed in various stem/progenitor cells. Compared with cell surface markers, the cellular intrinsic functional property ALDH activity is more generally accepted in different types of tumor, such as leukemia, liver, lung, breast, colon and head and neck cancers [16-21]. However, whether ALDH high activity is suitable as a marker to enrich DLBCL CSCs has not been reported, although the previous studies showed high expression of ALDH1A1, an isoform of $\mathrm{ALDH}$, mediated chemo-resistance and associated with worse prognosis in DLBCL by immunohistochemistry [22-24]. So ALDH high activity cells were sorted using Aldefluor assay kit by flow cytometry and explored the possibility as a marker of DLBCL CSCs in our study.

\section{Materials and Methods}

\section{Cell lines and cultures}

An EBV-transformed LCL was established. The EBV-transformed marmoset cell line B95-8 was purchased from Kunming Cell Bank of Chinese Academy of Sciences. It was grown to confluency, and infectious culture supernatants were collected and stored at $-80^{\circ} \mathrm{C}$ before use. A healthy donor samples of peripheral blood were separated by Ficoll-Hypaque gradient centrifugation to acquire peripheral blood mononuclear cells (PBMC). Six million PBMCs of $3 \mathrm{ml}$ complete medium was added to $3 \mathrm{ml}$ of B95-8 supernatant in a $25 \mathrm{~cm}^{2}$ culture flask. Clusters of cells were observed by a light microscopy about a week later and became larger over time. The cell culture medium was changed approximately every 3-4 days. The EBV positive DLBCL cell line (Farage) was purchased from China Center for Type Culture Collection. All the above cell lines were cultured in RPMI 1640 supplemented with 10\% fetal bovine serum (FBS), 1\% penicillin and streptomycinthe.
Flow cytometry analysis of CD45+CD19expression, and fluorescence-activated cell sorting of CD45+CD19- cells

To identify the surface markers of LCL, the antibodies conjugated with peridinin chlorophyll complex (Percp), allophycocyanin (APC), phycoerythrin (PE) or fluorescein isothiocyanate (FITC) and included IgG1 isotype controls (Percp, FITC, PE or APC) were used. The cells were labeled with CD45Percp, CD19-APC, CD20-PE, CD34-PE, CD3-PE, CD16-FITC, CD56-PE, CD14-FITC and were analyzed with flow cytometry (CantoII, BD Biosciences, San Jose, CA, USA). (Information of antibodies was provided in Table S1).

The LCL and Farage cells were incubated with CD45-Percp and CD19-APC and sorted by fluorescence-activated cell sorting (MoFLo, Beckman Coulter, CA, USA).

\section{Flow cytometry analysis of ALDH expression, and fluorescence-activated cell sorting of ALDH ${ }^{\text {high }}$ cells}

ALDH activity was measured using the ALDEFLUOR kit per protocol (Stem cell Technologies, Vancouver, BC, Canada). Cells were analyzed and sorted by flow cytometry (AriaII, BD Biosciences, San Jose, CA, USA). All FACS data were analyzed by the Flowjo software (Tree Star, Ashland, OR, USA).

\section{Clonal analyses in vitro}

The CytoSelect 96-Well Cell Transformation Assay (Cell Biolabs, San Diego, CA, USA) was used to assess colony formation. 2,500 and 1,250 cells per well were seeded in soft agar in the flat-bottomed 96-well culture dishes. After 14 days of incubation at $37^{\circ} \mathrm{C}$ in $5 \% \mathrm{CO} 2$, soft agar was solubilized. Then cells were incubated with the CyQUANT GR Dye. Colony formation was quantified by the Synergy HT plate reader and the Gen 5 software (BioTek, Shoreline, WA, USA). Three independent experiments were performed.

\section{Expression of stemness genes by western blotting (WB) analysis}

The cell lysates were prepared with ice-cold RIPA buffer and centrifuged (12000g for $15 \mathrm{~min}$ at $4^{\circ} \mathrm{C}$ ). The protein concentration was determined by

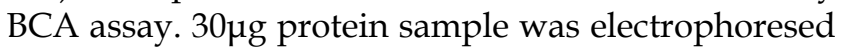
on a $10 \%$ SDS polyacrylamide gel and electroblotted onto polyvinylidene fluoride membranes. Membranes were incubated in 5\% non-fat milk 2 hours and then incubated with primary antibodies, including SOX2, OCT4, Nanog, ABCG2 and $\beta$-actin (Zsbio, Beijing, China) at $4^{\circ} \mathrm{C}$ overnight. After washing with 
Tris-buffered saline Tween 20 buffer, the membranes were incubated with secondary antibodies conjugated by horseradish peroxidase (HRP) for 2 hours at room temperature. Enhanced chemiluminescence reagent (HaiGene, Harbin, Heilongjiang, China) were used to visualize proteins. (Information of antibodies was provided in Table S1).

\section{Expression of stemness genes by reverse transcription-PCR (RT-PCR) analysis}

Total RNA was obtained using Trizol reagent (Invitrogen, Carlsbad, CA, USA) from the ALDH high and ALDH- Farage cells isolated by FACS. One-step RT-PCR kit (Qiagen, Valencia, CA, USA) was done for RT-PCR on the basis of the manufacturer's protocol. Glyceraldehyde-3-phosphate dehydrogenase (GAP$\mathrm{DH})$ was an internal standard control. The PCR primers sequences for ABCG2, Nanog, OCT4 and SOX2 were listed in the supplementary data (Table S2).

\section{Xenograft tumor experiments and in vivo tumorigenicity}

Immunodeficient NOD/SCID mice (6-8 weeks old) were purchased from Beijing Vital River Laboratory Animal Technology Co., Ltd. These mice were bred in a specific pathogen free (SPF) facility. First, $5 \times 10^{6}$ unsorted LCL cells were transplanted into NOD/SCID mice by intraperitoneal injection. Then $10^{2}, 10^{3}, 10^{4}, 10^{5}, 5 \times 10^{5}$, and $10^{6}$ cells of the $\mathrm{CD}^{2} 5^{+} \mathrm{CD} 19^{+}$and $\mathrm{CD} 45^{+} \mathrm{CD} 19-$ cells sorted from LCL and Farage cell line were transplanted by intraperitoneal injection into NOD/SCID mice, $10^{5}$, $5 \times 10^{5}$, and $10^{6}$ cell numbers were injected again. $1.5 \times 10^{2}, 1.5 \times 10^{3}, 1.5 \times 10^{4}$, and $1.5 \times 10^{5}$ cells of the ALDH $^{\text {high }}$ and ALDH ${ }^{-}$cells sorted from Farage cell line were also transplanted into NOD/SCID mice by intraperitoneal injection. Mice were kept until about 8 weeks when the mice showed discomfort or distress. All mice were killed at the same time points.

\section{Immunohistochemistry (IHC) of the xenograft tumors}

Xenograft tumors were made paraffin sections. The slides were heated and then deparaffinized. After antigen repair, 1 to 2 drops primary antibodies were added to slides and incubated. Then slides were incubated with 1 to 2 drops HRP-conjugated secondary antibody. Finally, slides were dehydrated, transparent and sealed. (Information of antibodies was provided in Supplementary Table S1).

\section{Detection of EBV by EBER ISH}

The infection of EBV was detected by EBER ISH (EBER DNA Probe, S30172; TRIPLEX, Fujian, China) according to the product manual.

\section{Statistical analysis}

The data were presented as mean $\pm S D$. The two-sided student's $t$ test was used to compare the data by statistical software R3.3.2, of which $\mathrm{P}<0.05$ was considered statistically significant.

\section{Results}

\section{The successful establishment and identification of LCL}

About 4 weeks later, LCL was established successfully. Then the LCL was characterized with 8 hematopoietic cell surface markers by FACS analysis. The lymphocyte surface marker of CD45 was positive. The LCL also expressed CD19 and CD20, and two B cell lineage markers, but was negative for the expression of hematopoietic stem cell (CD34), $\mathrm{T}$ cell (CD3), NK cell (CD16, CD56) and monocyte cell (CD14) (Fig. 1). The data suggests the LCL is of B cell lineage. To test whether the LCL cell line can be used as a model of lymphoma, the cells were xenotransplanted into NOD/SCID mice. The xenograft tumor had an expression of human CD20, CD19, CD79a, Ki67, Bcl-2, MUM-1 by immunohistochemistry (Supplementary Fig. S1). And the EBV was positive in the xenograft tumor by EBER ISH detection. Two experienced pathologists diagnosed the tumor as a pathological feature of EBV positive DLBCL. It is indicated that the LCL cell line as a model system served to investigate tumorigenesis of DLBCL is possible.

\section{The existence of CD45+CD19- cells population in LCL and Farage cell line}

Previous studies reported that minor CD45 ${ }^{+}$CD19- cells may identify CSCs in MCL [13-15]. In order to find out whether the $\mathrm{CD} 45^{+} \mathrm{CD} 19^{-}$cells were expressed in DLBCL, we analyzed LCL and Farage cells via flow cytometry. The $\mathrm{CD} 45^{+} \mathrm{CD} 19$ - cells accounted for $1-3 \%$ in the two cell lines (Fig. 2). A portion of $\mathrm{CD}_{4} 5^{+} \mathrm{CD} 19^{-}$cells and $\mathrm{CD} 45^{+} \mathrm{CD} 19^{+}$cells were sorted separately for the further studies. Post-sorting analyses showed these two subpopulations had a purity of $\geq 99 \%$ in the desired population (Fig. 2).

\section{CD45+CD19- cells are not more tumorigenic than the CD45+CD19+ cells}

In vivo, the identification of putative CSCs in immunodeficient xenograft model is the ultimate proof. To determine whether $\mathrm{CD} 45^{+} \mathrm{CD} 19$ - could serve as a marker for DLBCL, we also conducted xenotransplantation in NOD/SCID mice. When more than 100,000 cells were transplanted into the mice, both of the two sub-populations generated tumors. 
Compared with the same number of cells, the $\mathrm{CD} 45^{+} \mathrm{CD} 19^{+}$population generated more tumors (Table 1) and larger tumors $(\mathrm{p}<0.05$, Fig.3A). However, with a small number of cells (100 to10, 000) inoculated, two sub-populations did not generate a tumor (Table 1). Ki-67, the proliferative antigen, showed higher expression in $\mathrm{CD} 45^{+} \mathrm{CD} 19^{+}$xenograft tumor (Fig. 3B), which was consistent with the larger tumors in this sub-population.

Then, $\mathrm{CD} 45^{+} \mathrm{CD} 19^{+}$and $\mathrm{CD} 45^{+} \mathrm{CD} 19-$ cells were isolated from Farage cell line and similar results were observed. When $100,000 \mathrm{CD}^{2} 5^{+} \mathrm{CD} 19^{+}$cells were injected into the mice, the tumor incidence was $33.33 \%$ (two of six; Table 1). However, CD45+CD19cells did not give rise to any tumor (zero of six; Table 1 ) in the presence of the same number of these cells. With 1, 000, $000 \mathrm{CD}^{2} 5^{+} \mathrm{CD} 19^{+}$cells injected, we found a tumor incidence of $100 \%$ (six of six; Table 1), compared with $66.67 \%$ (four of six; Table 1) in CD $45^{+} \mathrm{CD} 19-$ cells. And tumors formed by $\mathrm{CD} 45^{+} \mathrm{CD} 19^{+}$cells were larger than those formed by CD45 ${ }^{+}$CD19- cells ( $p<0.05$, Fig. $4 \mathrm{~A}$ ). Immunohistochemical analysis showed increased Ki-67 expression in the $\mathrm{CD} 45^{+} \mathrm{CD} 19^{+}$derived tumors (Fig. 4B).
Table 1. Tumor-initiating capacity of limiting dilutions of CD $45^{+} \mathrm{CD} 19^{+}$and $\mathrm{CD} 45^{+} \mathrm{CD} 19^{-}$cells from the LCL and Farage cell lines

\begin{tabular}{|c|c|c|c|c|}
\hline Cell & \multicolumn{2}{|c|}{ LCL cell line } & \multicolumn{2}{|c|}{ Farage cell line } \\
\hline Cell type & CD4 & CD45+CD19- & CD4 & CD45+CD19- \\
\hline No. of cells injected & \multicolumn{2}{|c|}{ Tumors formed } & \multicolumn{2}{|c|}{ Tumors formed } \\
\hline $10^{6}$ & $5 / 6$ & $2 / 6$ & $6 / 6$ & $4 / 6$ \\
\hline $5 \times 10^{5}$ & $4 / 5$ & $0 / 6$ & $3 / 5$ & $3 / 6$ \\
\hline $10^{5}$ & $3 / 6$ & $1 / 6$ & $2 / 6$ & $0 / 6$ \\
\hline $10^{4}$ & $0 / 6$ & $0 / 6$ & $0 / 6$ & $0 / 6$ \\
\hline $10^{3}$ & $0 / 6$ & $0 / 6$ & $0 / 6$ & $0 / 6$ \\
\hline $10^{2}$ & $0 / 6$ & $0 / 6$ & $0 / 6$ & $0 / 6$ \\
\hline
\end{tabular}

To confirm tumorigenic activities were not enriched in the $\mathrm{CD} 45^{+} \mathrm{CD} 19$ - cells, we repeated tumor xenotransplantation experiments using purified CD $45^{+} \mathrm{CD} 19^{+}$cells and $\mathrm{CD}^{+} 5^{+} \mathrm{CD} 19^{-}$cells from LCL and Farage and observed similar results (Table S3; Fig. S2).

These results show that both $\mathrm{CD} 45^{+} \mathrm{CD} 19^{+}$and CD45 ${ }^{+} \mathrm{CD} 19-$ cells possess the tumor-initiating capacity at a certain number of cells, while $\mathrm{CD} 45^{+} \mathrm{CD} 19^{-}$ cells are not more tumorigenic than the $\mathrm{CD} 45^{+} \mathrm{CD} 19^{+}$ cells.
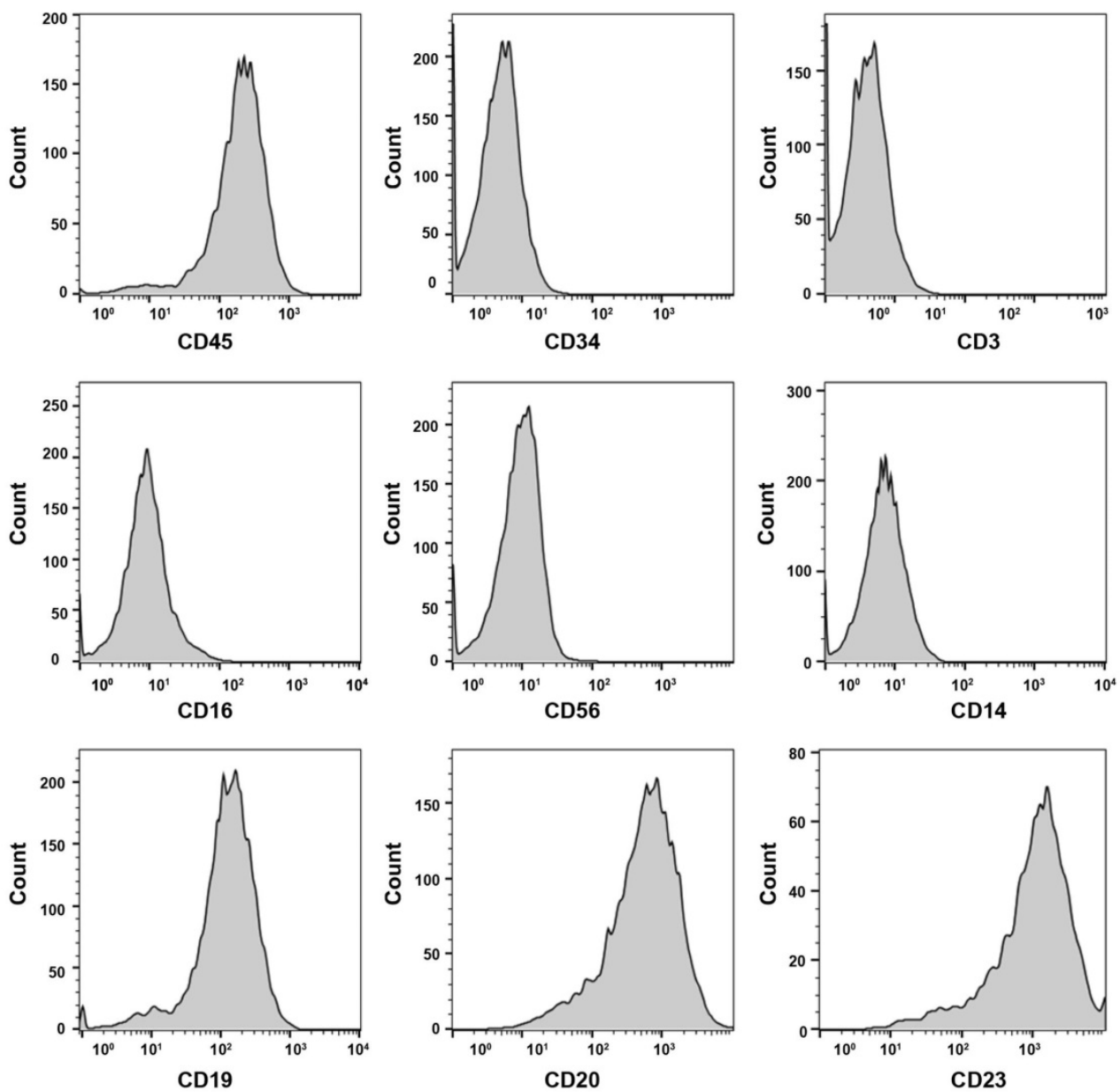

Figure 1. The surface markers of LCL by flow cytometry analysis. CD45, CD19, CD20 and CD23 are positive. 

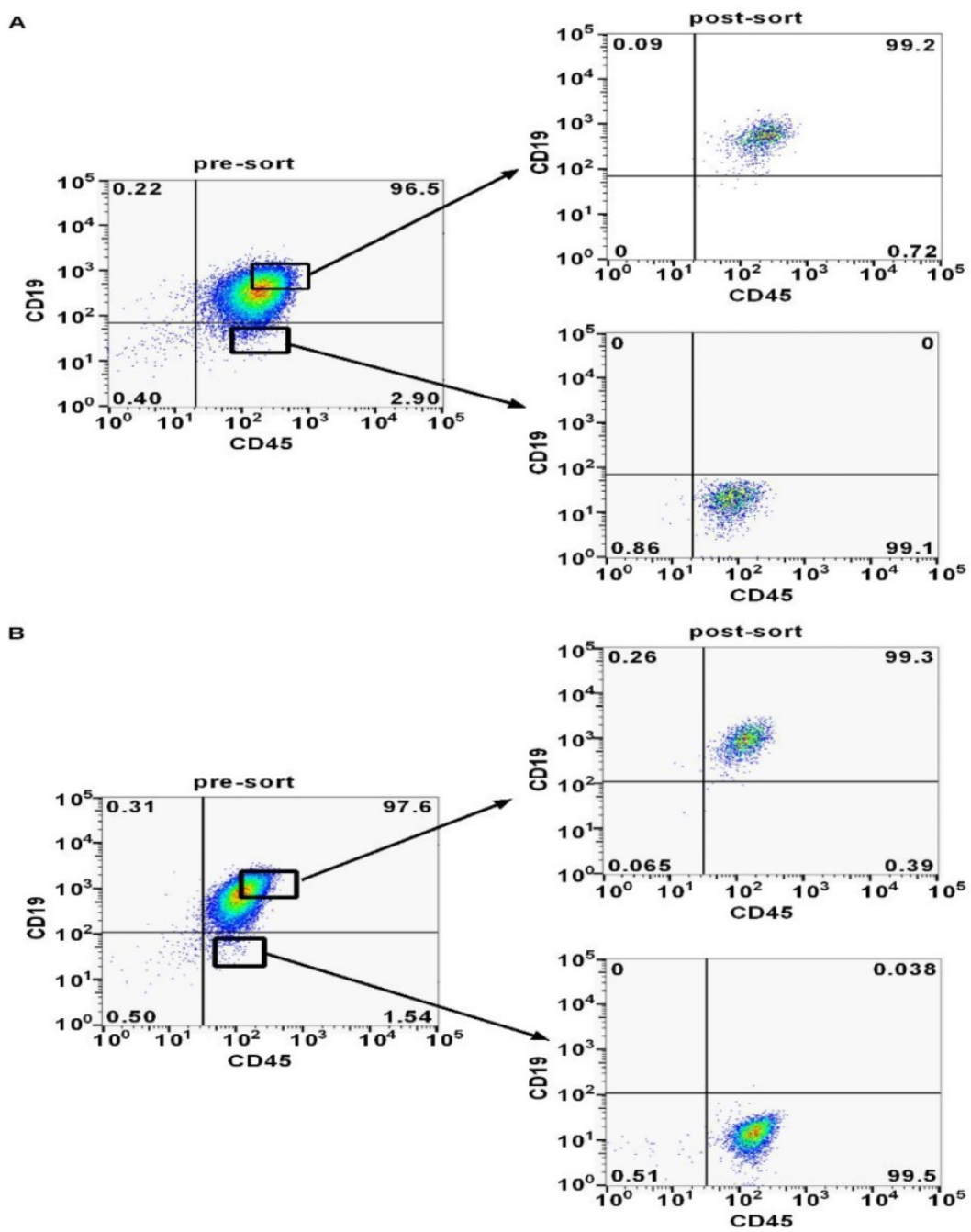

Figure 2. $\mathrm{CD}_{45}+\mathrm{CD} 19^{+}$and $\mathrm{CD} 45+\mathrm{CD} 19$ - cells were analyzed and sorted by flow cytometer. (A) The proportion of CD45+CD19- cells and the post-sort purity in $L C L$ cell line. (B) The proportion of $C D 45+C D 19$ - cells and the post-sort purity in Farage cell line.

\section{CD45+CD19+ cells have stronger clonogenicity than CD45+CD19- cells}

We further tested the colony formation ability in vitro, which partially evaluates the tumorigenicity of the cells in vitro $[25,26]$. Purified $C D 45^{+} \mathrm{CD} 19^{+}$and CD45 ${ }^{+} \mathrm{CD} 19-$ cells from LCL and Farage were used. As a result, $\mathrm{CD} 45^{+} \mathrm{CD} 19^{+}$cells showed greater colony formation than $\mathrm{CD}^{+} 5^{+} \mathrm{CD} 19$ - cells (Fig. 3C, 4C), which was in line with xenotransplantation results in vivo.

\section{The expression of stemness genes is similar between CD45+CD19+ cells and CD45+CD19- cells.}

The expression of stemness genes is also used to identify CSCs [27-30]. OCT4, SOX2, Nanog and ABCG2 are considered as important factors in the maintenance of stem cells. So, the expression of OCT4, SOX2, Nanog and ABCG2 were detected by WB analyses in our study. The result showed there was no difference between the $\mathrm{CD} 45^{+} \mathrm{CD} 19^{+}$and $\mathrm{CD} 45^{+} \mathrm{CD} 19^{-}$ cells in LCL and Farage cell line (Fig. 3D, 4D).

\section{ALDH ${ }^{\text {high }}$ cells are more tumorigenic than the ALDH- cells}

Our study indicated CD45 ${ }^{+} \mathrm{CD} 19^{-}$surface marker cannot identify CSCs populations in DLBCL. So, we further explored the ALDH activity which had been reported as a potential marker of CSCs in many tumors [31-33] in Farage cell line. In order to obtain ALDH ${ }^{\text {high }}$ cells, only about $10 \%$ of the most brightly stained cells were selected (Fig. 5A). After 1,500 $\mathrm{ALDH}^{\text {high }}$ cells were injected into the NOD/SCID mice, these cells gave rise to tumors $(40 \%$ incidence, two of five; Table 2). With 15,000 ALDH ${ }^{\text {high }}$ cells injected, tumor incidence was $80 \%$ (four of five; Table 2). With 150,000 ALDH ${ }^{\text {high }}$ cells injected, all five mice generated tumors (Table 2). In contrast, no tumor was generated with 1,500 ALDH- cells (zero of five; Table 2). Tumor did arise when 15,000 ALDH- cells were $^{-}$ injected (two of five; Table 2). Although ALDH-cells 
generated tumors, the tumors derived by ALDH ${ }^{\text {high }}$ cells were larger than those induced by ALDH- cells (Fig. 5B). These results showed that CSCs were enriched in the ALDH high cells.

Table 2. Tumor-initiating capacity of limiting dilutions of $A L D H^{\text {high }}$ and $A L D H-$ cells from the Farage cell line

\begin{tabular}{lll}
\hline Cell & Farage cell line & \\
\hline Cell type & ALDH $^{\text {high }}$ & ALDH- \\
\hline No. of cells injected & Tumors formed & \\
\hline $1.5 \times 10^{5}$ & $5 / 5$ & $4 / 5$ \\
$1.5 \times 10^{4}$ & $4 / 5$ & $2 / 5$ \\
$1.5 \times 10^{3}$ & $2 / 5$ & $0 / 5$ \\
$1.5 \times 10^{2}$ & $0 / 5$ & $0 / 5$ \\
\hline
\end{tabular}

\section{ALDHhigh cells have stronger clonogenicity than ALDH- cells}

The colony formation of ALDH ${ }^{\text {high }}$ and ALDH-in Farage cell line was also identified. In accordance with the tumorigenicity, the ALDH ${ }^{\text {high }}$ cells had stronger colony formation ability than ALDH- cells. (Fig. 5C).

\section{The expression of stemness genes is similar between ALDH high and ALDH-cells}

However, the expression levels of stemness genes did not show any significant difference between the ALDH high and $\mathrm{ALDH}^{-}$cells (Fig. 5D, 5E). Most probably, although the ALDH ${ }^{\text {high }}$ cells enrich CSCs, its purity is not high enough. Therefore, it is difficult to obtain the difference between the two subgroups.

\section{Discussion}

CSCs, as defined by the American Association for Cancer Research Workshop denotes cells within a tumor that possess the capacity to self-renewal and to differentiate into the heterogeneous lineages of cancer cells that constitute the tumor [34]. The CSCs theory suggests that tumor growth is drived by a small number of CSCs hidden in cancers. It is helpful to explain some clinical phenomenon, such as recurrence after initially successful chemotherapy and/or radiotherapy, tumor dormancy, and metastasis. CSCs were identified in many common types of cancer, including leukemia, breast cancer, brain cancer, colorectal cancer and so on. The CSCs theory has stimulated therapeutic strategies for these tumors, not aimed at eliminating tumor bulk, but rather at eradicating CSCs, the cell which maintains tumor growth [35]. Isolation of this cell subpopulation by special markers is an important step in identifying these properties. Although CD34+CD38- [6, 7], CD133 ${ }^{+}$ [8] and $\mathrm{CD} 44^{+} \mathrm{CD} 24-$ [9-11] have been widely used as CSCs markers in human acute myeloid leukemia, brain tumor and breast cancer respectively. However, there are still no distinct markers of CSCs in many cancer subtypes, including lymphoma.
A
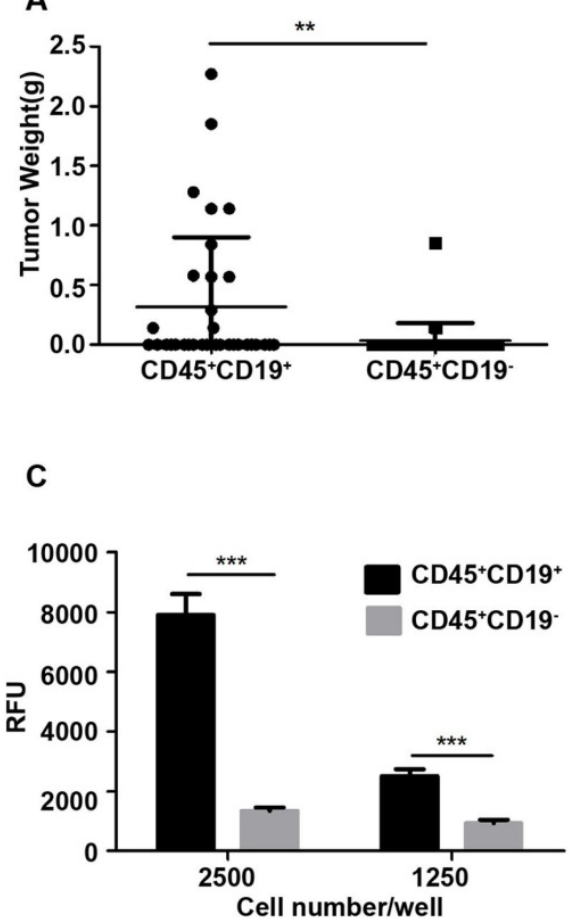

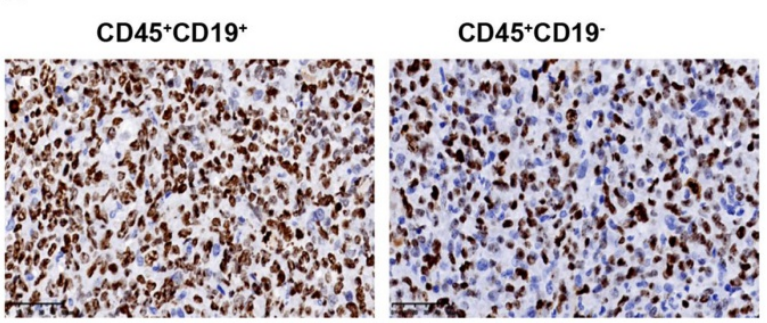

D

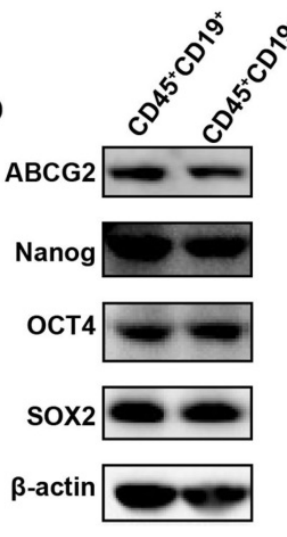

Figure 3. Characterization of CD45+CD19+ and CD45+CD19- cells in LCL cell line. (A) the weight of tumors generated by CD45+CD19+ cells were higher than $C D 45+C D 19$ - cells, *p $\leq 0.05$. (B) Ki-67 analysis of $C D 45+C D 19+$ and $C D 45+C D 19$ - cells derived tumor xenografts by IHC $(\times 400)$. (C) cells were plated at clone density ( 2500 cells and 1250 cells per well) and cultured for 14 days, colony formation was quantified using the fluorescent CyQUANT GR Dye. Three independent experiments were performed, ${ }^{* * *} p \leq 0.001$. (D) the expression levels of ABCG2, Nanog, OCT4 and SOX2 were evaluate. $\beta$-actin was used as a loading control. There was no difference between the two groups. 
A
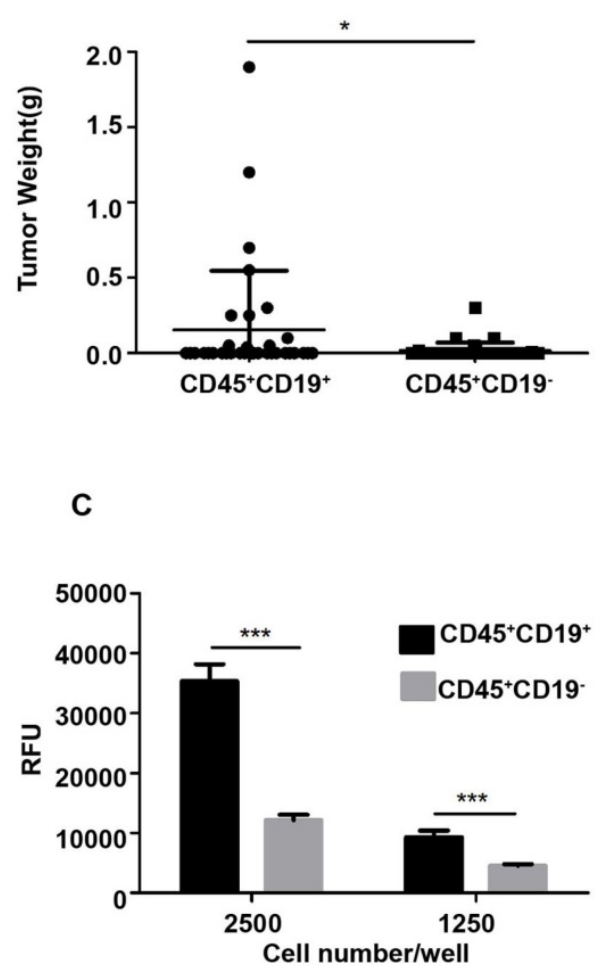

B
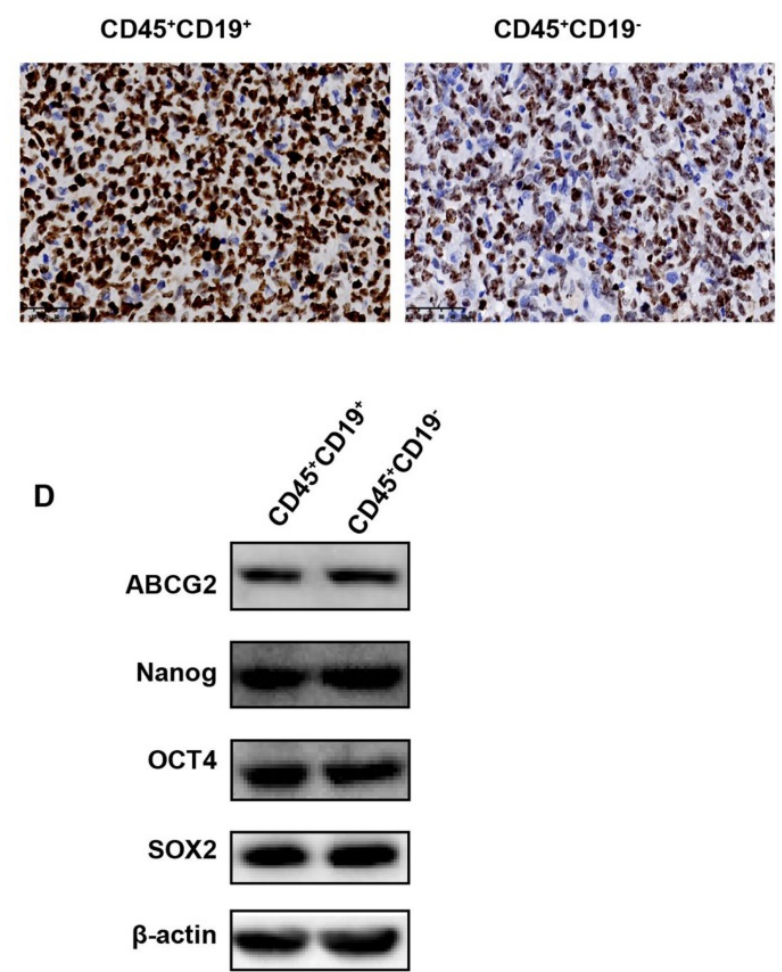

Figure 4. Characterization of CD45+CD19+ and CD45+CD19- cells in Farage cell line. (A) the weight of tumors generated by $C D 45+C D 19+$ cells were higher than $C D 45+C D 19$ - cells, $* * p \leq 0.01$. (B) Ki-67 analysis of $C D 45+C D 19+$ and $C D 45+C D 19$ - cells derived tumor xenografts by $1 \mathrm{HC}(\times 400)$. (C) cells were plated at clone density ( 2500 cells and 1250 cells per well) and cultured for 14 days, colony formation was quantified using the fluorescent CyQUANT GR Dye. Three independent experiments were performed. ${ }^{* * *} p \leq 0.001$. (D) the expression levels of ABCG2, Nanog, Oct 4 and SOX2 were evaluated. $\beta$-actin was used as a loading control. There was no difference between the two groups.

NHL is a pathologic type of B cell lymphoma, including DLBCL, chronic lymphocytic leukemia/ small lymphocytic lymphoma (CLL/SLL), follicular lymphoma (FL), MCL, and so on. Among these types of tumor, $\mathrm{CD} 45^{+} \mathrm{CD} 19-$ has been identified as a potential marker of CSCs in MCL [13-15]. So, we also explored the possibility of $\mathrm{CD}^{+} 5^{+} \mathrm{CD} 19^{-}$as a potential marker of DLBCL CSCs in vivo and in vitro. However, both of $\mathrm{CD} 45^{+} \mathrm{CD} 19-$ cells and $\mathrm{CD} 45^{+} \mathrm{CD} 19^{+}$ cells did not generate tumors until more than 100,000 cells inoculated in NOD/SCID mice, even CD45+ $\mathrm{CD} 19^{+}$cells generated more and larger tumors, as well as the soft agar colony formation in vitro. As for CSCs, one important ability is to form tumors at low cell numbers. In theory, injection of a single CSC might generate tumor in xenotransplantation mouse model [36]. Most tests on CSCs-induced tumorigenesis have used 100 1,000 cells as the smallest number of cells injected [37-42]. Therefore, $\mathrm{CD} 45^{+} \mathrm{CD} 19^{-}$may not be suitable as a marker of CSCs in DLBCL. Only 100 CD45 ${ }^{+}$CD19- cells isolated from the PBMCs of MCL patients generated tumors [13], however, CD45 CD19- cells sorted from the DLBCL cell lines did not generate tumors at the low cell densities in our study. The possible reasons are as follows. Firstly, the different pathogenesis of MCL and DLBCL; Secondly, the role of EBV. Our cell lines are EBV positive, whereas all MCL patients are EBV negative; Thirdly, the role of the microenvironment. The $\mathrm{CD} 45^{+} \mathrm{CD} 19$ cells were isolated from the PBMCs of MCL patients who were in the leukemic phase. As disease progresses, the change of the microenvironment might cause the different markers of CSCs. Moreover, both $\mathrm{CD} 45^{+} \mathrm{CD} 19-$ cells and $\mathrm{CD} 45^{+} \mathrm{CD} 19^{+}$cells sorted from the DLBCL cell lines generated tumors with enough number of cells injected in our study. This was consistent with the previous study in MCL, which the $\mathrm{CD} 45^{+} \mathrm{CD} 19^{+}$cells isolated from the MCL cell lines also generated tumors with $5 \times 10^{5}$ and $10^{6}$ cells injected [13]. We performed the experiments twice by using LCL and Farage cell lines and obtained similar results. These results suggest not only CD $45^{+}$CD19- but also CD $45^{+} \mathrm{CD} 19^{+}$cells isolated from the cell lines can drive tumors as long as enough cells are transplanted in mice. This phenomenon may be explained by the "clonal model", which suggests that each cell within a tumor has equal capacity to generate new tumors [43]. So $\mathrm{CD} 45^{+} \mathrm{CD} 19-$ is not suitable as a marker of CSCs in DLBCL, how about the ALDH activity? 
A
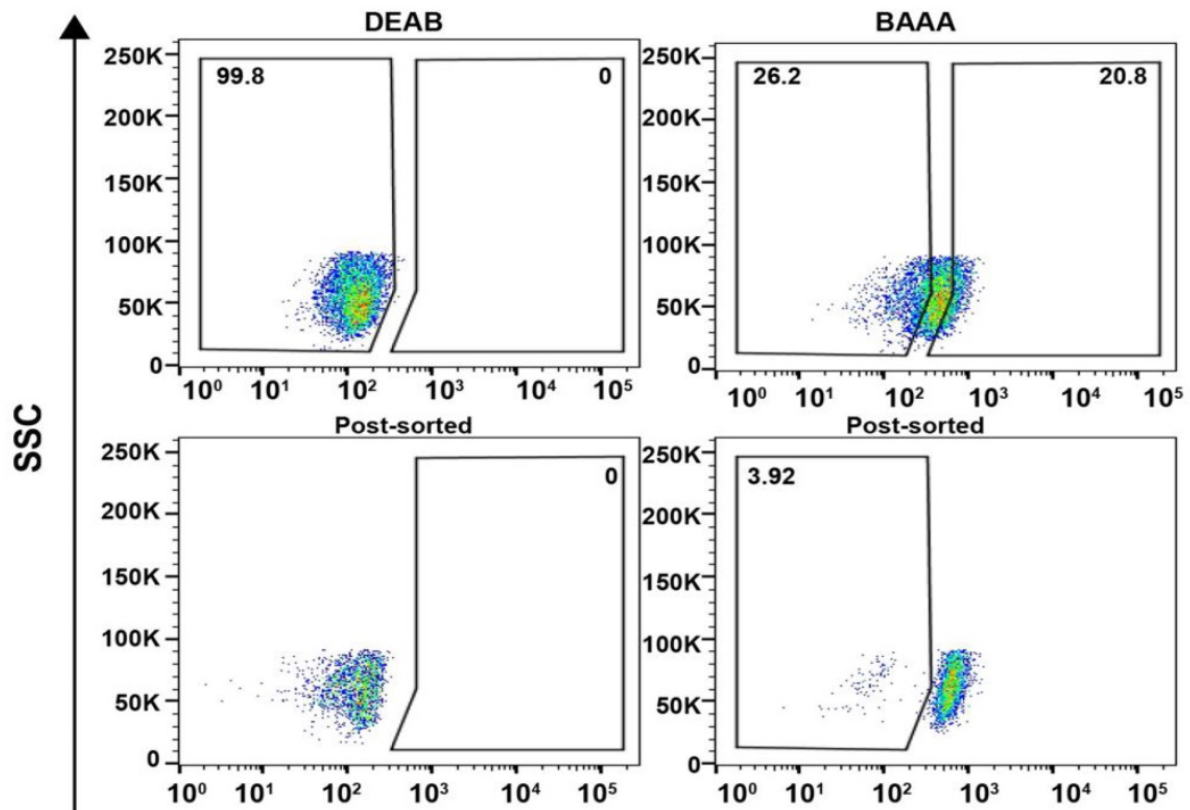

ALDH

B

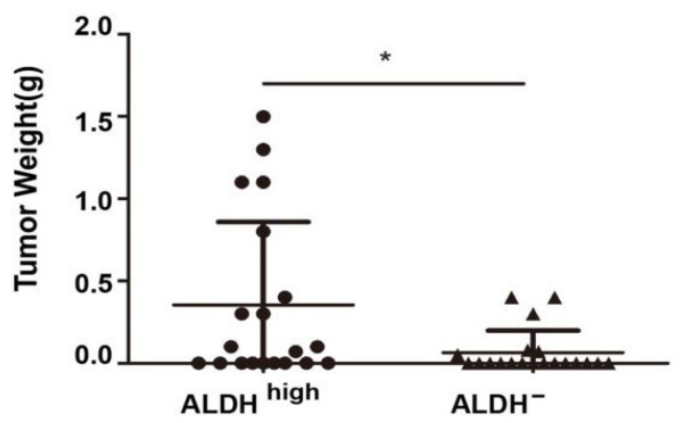

D

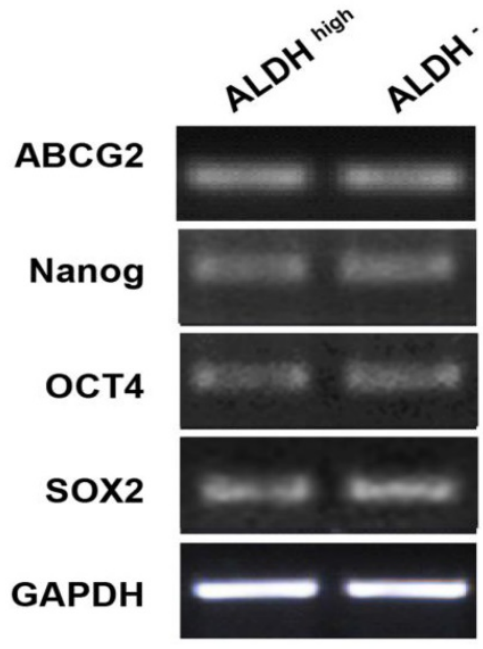

C

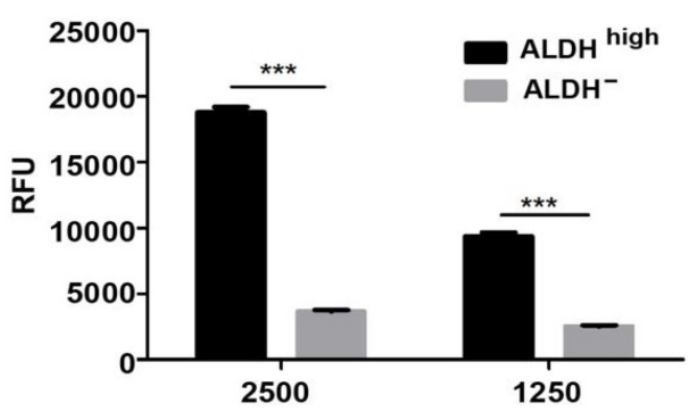

Cell number/well

E

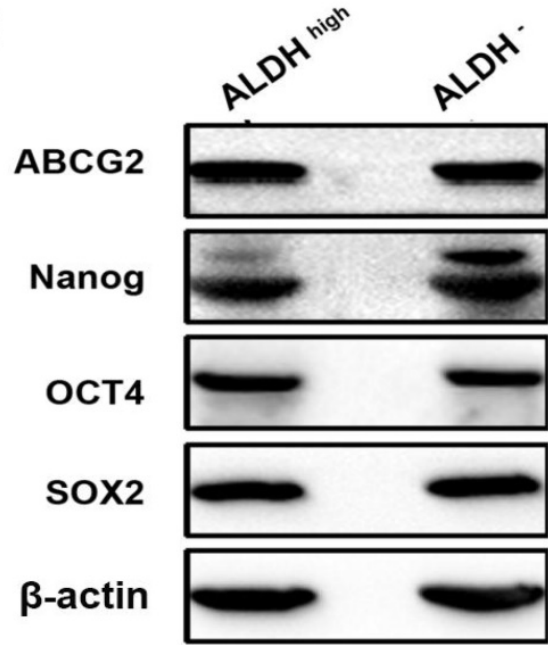

Figure 5. Characterization of ALDHhigh and ALDH- cells in Farage cell line. (A) The proportion of ALDHhigh cells and the post-sort purity in Farage cell line. (B) the weight of tumors generated by ALDHhigh cells were higher than ALDH- cells. ${ }^{*} \mathrm{p} \leq 0.05$. (C) cells were plated at clone density ( 2500 cells and 1250 cells per well) and cultured for 14 days, colony formation was quantified using the fluorescent CyQUANT GR Dye. Three independent experiments were performed. *** $\leq 0.001$. (D) and (E) the expression levels of ABCG2, Nanog, Oct4 and SOX2 were evaluated by RT-PCR and WB analysis. GAPDH and $\beta$-actin were used as loading controls respectively. There was no difference between the two groups. 
High ALDH activity has been demonstrated in CSCs of many tumor types, including MCL [44] and Burkitt lymphoma [45]. However, it has not been reported as a marker of CSCs in DLBCL, although ALDH1 expression was immunohistochemically examined in DLBCL in the previous study [22-24]. In our study, ALDHhigh cells were sorted using Aldefluor assay kit (StemCell Technologies, Durham, NC, USA) by flow cytometry and identified as a marker of CSCs in DLBCL. The results revealed 1,500 ALDH ${ }^{\text {high }}$ cells generated tumors while same number of ALDH- cells did not. ALDH ${ }^{\text {high }}$ cells generated more and larger tumors than ALDH- cells when both of two subgroups generated tumors with more cells injected. The similar result was obtained in vitro clonogenicity experiments. These data suggest ALDH activity identifies a population of DLBCL cells enriched for CSCs activity. However, 150 ALDH high cells cannot induce tumors in our study. Maybe ALDH high population is still heterogeneous, which consists of subsets of cells with different tumorigenic potential. Certainly, ALDH ${ }^{\text {high }}$ cells combining with definitive CSCs surface markers may further enrich CSCs population in other studies, such as hepatocellular carcinoma, head and neck carcinoma and ovarian cancer [17, 21, 32]. Nevertheless, no specific surface markers have been found in DLBCL nor did we identify CSCs by combining ALDH activity with surface markers in DLBCL.

Expression of stemness genes is also used to identify CSCs. OCT4, Sox2, and Nanog are transcription factors that are analyzed in most studies. They are often expressed in pluripotent embryonic stem cells, germ cells, certain committed progenitors and cancer cells [35]. ABCG2 is one of the major mediators in the $\mathrm{ABC}$ family of transporter proteins, which has been also used to identify both normal cells and CSCs [46]. In our study, we found these genes were similarly expressed in $\mathrm{CD}_{4} 5^{+} \mathrm{CD} 19^{+}$cells, CD45 ${ }^{+} \mathrm{CD} 19-$ cells, ALDH- cells and ALDH high cells. As mentioned above, CSCs are not enriched in CD $45^{+} \mathrm{CD} 19-$ cells and $\mathrm{CD} 45^{+} \mathrm{CD} 19^{+}$cells, so we can understand the similar expression of these genes. To our surprise, this phenomenon even happened in $\mathrm{ALDH}^{-}$cells and ALDHhigh cells, which maybe because the purity of enriched CSCs in ALDH high cells is not high enough or other unknown related genes exist. So the expression of stemness genes regulated ALDHhigh cells will be performed by gene expression profile or gene sequencing in order to obtain sufficient verifications of ALDHhigh cells in our future work. On the other hand, perhaps their expression is a feature of malignant transformation and not exclusive to CSCs [36].
Above all, CSCs are not enriched in the CD45 ${ }^{+}$CD19- cells but in the ALDH ${ }^{\text {high }}$ cells of DLBCL cell lines although the tumorigenic ability of $\mathrm{ALDH}^{\text {high }}$ cells is limited because its purity is not high enough. ALDH activity may be used as a marker of CSCs in DLBCL, which will be helpful for developing the prognosis and therapeutic strategies. We also hope to provide an early warning indicator for monitoring the occurrence of lymphoma in patients with EBV infection by regularly detecting the expression of ALDH activity, since EBV play an important role in the pathogenesis of DLBCL. And the stemness and tumorigenic properties of ALDHhigh cells in EBV negative DLBCL also deserve further exploration.

\section{Abbreviations}

CSCs: cancer stem cells; DLBCL: diffuse large B cell lymphoma; MCL: mantle cell lymphoma; ALDH: aldehyde dehydrogenase; NHL: nonHodgkin's lymphoma; EBV: Epstein-Barr virus; LCL: lymphoblastoid cell line; SP: side population; PBMC: peripheral blood mononuclear cells; FBS: fetal bovine serum; Percp: peridinin chlorophyll complex; APC: allophycocyanin; PE: phycoerythrin; FITC: fluorescein isothiocyanate; WB: western blotting; RT-PCR: reverse transcription-PCR; GAPDH: Glyceraldehyde3-phosphate dehydrogenase; IHC: Immunohistochemistry; SPF: specific pathogen free; CLL/SLL: chronic lymphocytic leukemia/small lymphocytic lymphoma; FL: follicular lymphoma.

\section{Supplementary Material}

Supplementary figures and tables.

http://www.jcancer.org/v11p0142s1.pdf

\section{Acknowledgements}

\section{Funding}

This work was supported by grants from the Major State Basic Research Development Program of China (973 program): grant no. 2013CB967200; and the Innovative Research Project for Postgraduates of Harbin Medical University: grant no. YJSCX201401HYD.

\section{Ethics statement}

The study was approved by the First Affiliated Hospital of Harbin Medical University Ethics Committee (201672), and the animal protocol was approved by the First Affiliated Hospital of Harbin Medical University Animal Care Committee (2017007). 


\section{Authors' Contributions}

\section{Conception and design}

Yongguo Li and Shupeng Song

\section{Development of methodology}

Shupeng Song, Yinghua Lan and Kaili Zhang

\section{Acquisition of data}

Shupeng Song, Kaili Zhang, Yanxin Huang,

Mingyan $\mathrm{Xu}$ and Shuangxing $\mathrm{Li}$

\section{Analysis and interpretation of data}

Shupeng Song, Yinghua Lan and Yongguo Li

Writing, review, and/or revision of the manuscript

Shupeng Song, Yunping Luo, Yinghua Lan and Yongguo Li

\section{Administrative, material or technical support \\ Shupeng Song, Kaili Zhang, Xue Guan, Jie Jiang,}

Tao Yang and Zhiyu Liu

\section{Study supervision}

Shupeng Song, Yinghua Lan and Yongguo Li.

\section{Competing Interests}

The authors have declared that no competing interest exists.

\section{References}

1. Li S, Young KH, Medeiros LJ. Diffuse large B-cell lymphoma. Pathology. 2018; 50: 74-87.

2. Healy JA, Dave SS. The role of EBV in the pathogenesis of diffuse large B cell lymphoma. Curr Top Microbiol Immunol. 2015; 390: 315-37.

3. Thomas JA, Hotchin NA, Allday MJ, Amlot P, Rose M, Yacoub M, et al. Immunohistology of Epstein-Barr virus-associated antigens in B cell disorders from immunocompromised individuals. Transplantation. 1990; 49: 944-53.

4. Hui-Yuen J, McAllister S, Koganti S, Hill E, Bhaduri-McIntosh S. Establishment of Epstein-Barr virus growth-transformed lymphoblastoid cell lines. J Vis Exp. 2011. doi: 10.3791/3321.

5. Miyazaki K. Treatment of diffuse large B-cell lymphoma. J Clin Exp Hematop. 2016; 56: 79-88.

6. Bonnet D, Dick JE. Human acute myeloid leukemia is organized as a hierarchy that originates from a primitive hematopoietic cell. Nat Med. 1997; 3: 730-7.

7. Lapidot T, Sirard C, Vormoor J, Murdoch B, Hoang T, Caceres-Cortes J, et al. A cell initiating human acute myeloid leukaemia after transplantation into SCID mice. Nature. 1994; 367: 645-8.

8. Singh SK, Clarke ID, Terasaki M, Bonn VE, Hawkins C, Squire J, et al. Identification of a cancer stem cell in human brain tumors. Cancer Res. 2003; 63: 5821-8.

9. Al-Hajj M, Wicha MS, Benito-Hernandez A, Morrison SJ, Clarke MF. Prospective identification of tumorigenic breast cancer cells. Proc Natl Acad Sci U S A. 2003; 100: 3983-8.

10. Ponti D, Costa A, Zaffaroni N, Pratesi G, Petrangolini G, Coradini D, et al. Isolation and in vitro propagation of tumorigenic breast cancer cells with stem/progenitor cell properties. Cancer Res. 2005; 65: 5506-11.

11. Perrone G, Gaeta LM, Zagami M, Nasorri F, Coppola R, Borzomati D, et al. In situ identification of CD44+/CD24- cancer cells in primary human breast carcinomas. PLoS One. 2012; 7: e43110.

12. Lee MR, Ju HJ, Kim BS, Ko YH, Kim WS, Kim SJ. Isolation of side population cells in B-cell non-Hodgkin's lymphomas. Acta Haematol. 2013; 129: 10-7.
13. Chen Z, Ayala P, Wang M, Fayad L, Katz RL, Romaguera J, et al. Prospective isolation of clonogenic mantle cell lymphoma-initiating cells. Stem Cell Res. 2010; 5: 212-25.

14. Jung HJ, Chen Z, McCarty N. Stem-like tumor cells confer drug resistant properties to mantle cell lymphoma. Leuk Lymphoma. 2011; 52: 1066-79.

15. Kim SM, Lee ST, Ryu KJ, Kim HJ, Kim SH, Ko YH, et al. A subset of CD45+/CD19 - cells in bone marrow may be associated with clinical outcomes of patients with mantle cell lymphoma. Leuk Lymphoma. 2015; 56: 3052-7.

16. Ran D, Schubert M, Pietsch L, Taubert I, Wuchter P, Eckstein V, et al. Aldehyde dehydrogenase activity among primary leukemia cells is associated with stem cell features and correlates with adverse clinical outcomes. Exp Hematol. 2009; 37: 1423-34.

17. Ma S, Chan KW, Lee TK, Tang KH, Wo JY, Zheng BJ, et al. Aldehyde dehydrogenase discriminates the CD133 liver cancer stem cell populations. Mol Cancer Res. 2008; 6: 1146-53.

18. Jiang F, Qiu Q, Khanna A, Todd NW, Deepak J, Xing L, et al. Aldehyde dehydrogenase 1 is a tumor stem cell-associated marker in lung cancer. Mol Cancer Res. 2009; 7: 330-8.

19. Marcato P, Dean CA, Pan D, Araslanova R, Gillis M, Joshi M, et al. Aldehyde dehydrogenase activity of breast cancer stem cells is primarily due to isoform ALDH1A3 and its expression is predictive of metastasis. Stem Cells. 2011; 29: 32-45.

20. Giraud J, Failla LM, Pascussi JM, Lagerqvist EL, Ollier J, Finetti P, et al. Autocrine secretion of progastrin promotes the survival and self-renewal of colon cancer stem-like cells. Cancer Res. 2016; 76: 3618-28.

21. Chen YC, Chen YW, Hsu HS, Tseng LM, Huang PI, Lu KH, et al. Aldehyde dehydrogenase 1 is a putative marker for cancer stem cells in head and neck squamous cancer. Biochem Biophys Res Commun. 2009; 385: 307-13.

22. Jiang J, Liu Y, Tang Y, Li L, Zeng R, Zeng S, et al. ALDH1A1 induces resistance to CHOP in diffuse large B-cell lymphoma through activation of the JAK2/STAT3 pathway. Onco Targets Ther. 2016; 9: 5349-60.

23. Song YH, Zhong MZ, Gan PP, Yi PY, Tang YH, Liu YP, et al. ALDH1A1 mediates resistance of diffuse large B cell lymphoma to the CHOP regimen. Tumour Biol. 2014;35:11809-17.

24. Fujita S, Morii E, Rahadiani N, Wada N, Hori Y, Ikeda JI, et al. Significance of aldehyde dehydrogenase 1 expression in stromal cells of diffuse large B-cell lymphoma. Ther Med. 2011;2:591-4.

25. Franken NA, Rodermond HM, Stap J, Haveman J, van Bree C. Clonogenic assay of cells in vitro. Nat Protoc. 2006; 1: 2315-9.

26. Mannelli G, Magnelli L, Deganello A, Busoni M, Meccariello G, Parrinello G, et al. Detection of putative stem cell markers, $\mathrm{CD} 44 / \mathrm{CD} 133$, in primary and lymph node metastases in head and neck squamous cell carcinomas. A preliminary immunohistochemical and in vitro study. Clin Otolaryngol. 2015; 40: 312-20.

27. Tirino V, Desiderio V, Paino F, De Rosa A, Papaccio F, Fazioli F, et al. Human primary bone sarcomas contain CD133+ cancer stem cells displaying high tumorigenicity in vivo. FASEB J. 2011; 25: 2022-30.

28. Albers AE, Chen C, Koberle B, Qian X, Klussmann JP, Wollenberg B, et al. Stem cells in squamous head and neck cancer. Crit Rev Oncol Hematol. 2012; 81: 224-40.

29. Eramo A, Haas TL, De Maria R. Lung cancer stem cells: tools and targets to fight lung cancer. Oncogene. 2010; 29: 4625-35.

30. Dunning NL, Laversin SA, Miles AK, Rees RC. Immunotherapy of prostate cancer: should we be targeting stem cells and EMT? Cancer Immunol Immunother. 2011; 60: 1181-93.

31. Bai S, Ingram P, Chen YC, Deng N, Pearson A, Niknafs YS, et al. EGFL6 regulates the asymmetric division, maintenance, and metastasis of ALDH+ ovarian cancer cells. Cancer Res. 2016; 76: 6396-409.

32. Silva IA, Bai S, McLean K, Yang K, Griffith K, Thomas D, et al. Aldehyde dehydrogenase in combination with CD133 defines angiogenic ovarian cancer stem cells that portend poor patient survival. Cancer Res. 2011; 71: 3991-4001.

33. Nguyen PH, Giraud J, Chambonnier L, Dubus P, Wittkop L, Belleannee $G$, et al. Characterization of biomarkers of tumorigenic and chemoresistant cancer stem cells in human gastric carcinoma. Clin Cancer Res. 2017; 23: 1586-97.

34. Clarke MF, Dick JE, Dirks PB, Eaves CJ, Jamieson CH, Jones DL, et al. Cancer stem cells--perspectives on current status and future directions: AACR Workshop on cancer stem cells. Cancer Res. 2006; 66: 9339-44.

35. Batlle E, Clevers H. Cancer stem cells revisited. Nat Med. 2017; 23: 1124-34.

36. Tirino V, Desiderio V, Paino F, De Rosa A, Papaccio F, La Noce M, et al. Cancer stem cells in solid tumors: an overview and new approaches for their isolation and characterization. FASEB J. 2013; 27: 13-24.

37. O'Brien CA, Pollett A, Gallinger S, Dick JE. A human colon cancer cell capable of initiating tumour growth in immunodeficient mice. Nature. 2007; 445: 106-10. 
38. Ricci-Vitiani L, Lombardi DG, Pilozzi E, Biffoni M, Todaro M, Peschle C, et al. Identification and expansion of human colon-cancer-initiating cells. Nature. 2007; 445: 111-5.

39. Hurt EM, Kawasaki BT, Klarmann GJ, Thomas SB, Farrar WL. CD44+ CD24(-) prostate cells are early cancer progenitor/stem cells that provide a model for patients with poor prognosis. Br J Cancer. 2008; 98: 756-65.

40. Dalerba P, Dylla SJ, Park IK, Liu R, Wang X, Cho RW, et al. Phenotypic characterization of human colorectal cancer stem cells. Proc Natl Acad Sci U S A. 2007; 104: 10158-63.

41. Prince ME, Sivanandan R, Kaczorowski A, Wolf GT, Kaplan MJ, Dalerba $P$, et al. Identification of a subpopulation of cells with cancer stem cell properties in head and neck squamous cell carcinoma. Proc Natl Acad Sci U S A. 2007; 104: 973-8.

42. Collins AT, Berry PA, Hyde C, Stower MJ, Maitland NJ. Prospective identification of tumorigenic prostate cancer stem cells. Cancer Res. 2005; 65: 10946-51.

43. O'Connor ML, Xiang D, Shigdar S, Macdonald J, Li Y, Wang T, et al. Cancer stem cells: A contentious hypothesis now moving forward. Cancer Lett. 2014; 344: 180-7.

44. Brennan SK, Meade B, Wang Q, Merchant AA, Kowalski J, Matsui W. Mantle cell lymphoma activation enhances bortezomib sensitivity. Blood. 2010; 116: 4185-91.

45. Ryu KJ, Park C, Hong M, Ko YH, Kim WS, Kim SJ. FOXO4 expression is related to stem cell-like properties and resistance to treatment in diffuse large B-cell lymphoma. Oncotarget. 2017; 8: 2466-76.

46. Hirschmann-Jax C, Foster AE, Wulf GG, Nuchtern JG, Jax TW, Gobel U, et al. A distinct "side population" of cells with high drug efflux capacity in human tumor cells. Proc Natl Acad Sci U S A. 2004; 101: 14228-33. 